\title{
Fatal biliary-pulmonary fistula due to a proximally migrating biliary stent
}
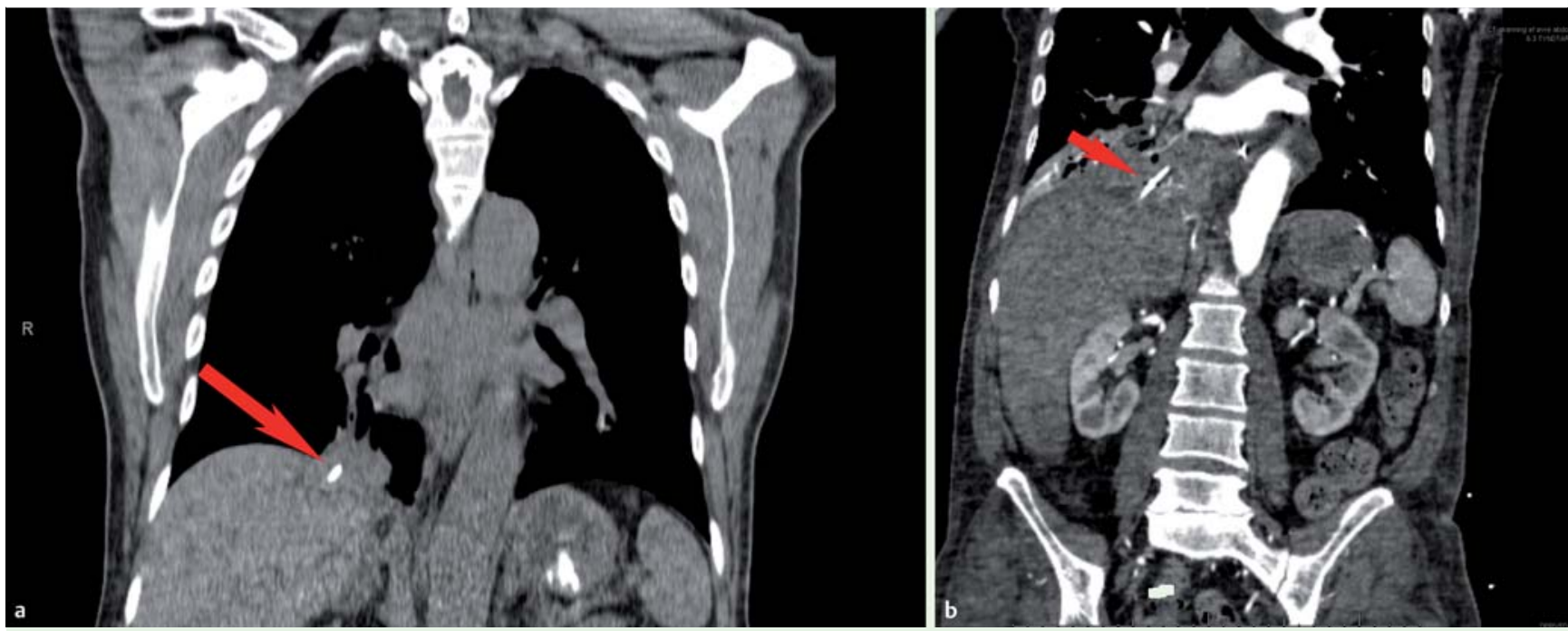

Fig. 1 Computed tomography (CT) scan showing the stent position (arrow): a in 2010, when it was located within a triangular infiltrate, possibly penetrating into the right lower lobe; $\mathbf{b}$ in 2013 , when there was clear penetration of the stent into the right lower lobe.

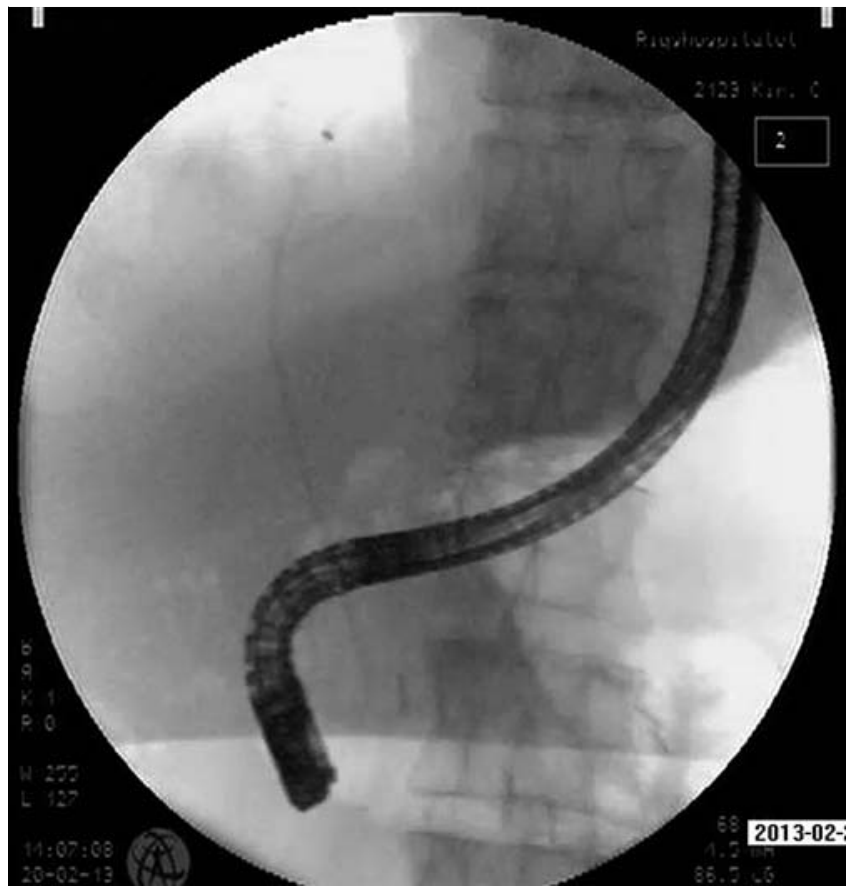

Biliary stent migration occurs in approximately $6 \%$ of patients, with the stent migrating proximally in half of cases [1, 2]. Endoscopic retrieval of the proximally migrated stent can be problematic; however, good success rates are achievable [3]. In February 2013, a 62-year-old man with known recurrent pneumonia presented with shortness of breath and a productive
Fig. 2 Image taken during endoscopic retrograde cholangiopancreatography (ERCP) before extraction showing the full length of the biliary stent. cough that had been present for 1 week. As he was in respiratory distress, he was transferred to the intensive care unit where bile-like material was suctioned from his airways.

The patient had had a biliary stent in place since 1999 following traumatic necrosis of the common bile duct and gallbladder. The stent, which stretched from the papil- la to the right hepatic duct, had been replaced in January 2000. In August 2000, removal of the stent had failed, but as the patient was asymptomatic, he was discharged without follow-up.

A computed tomography (CT) scan from 2010 had shown the stent to be near the right hemidiaphragm, possibly penetrating into the thoracic cavity ( Fig. 1 a). A new CT scan in 2013 showed the biliary stent was now located in the right thoracic cavity ( $\bullet$ Fig. 1 b).

On day 9 following admission, the second of two endoscopic retrograde cholangiopancreatography (ERCP) procedures was successful ( $\bullet$ Fig. 2). The stent, after being pushed upwards to detach it from the wall of the common bile duct, was retrieved using a Memory Basket (7-Fr Hard Wire, $2 \times 4 \mathrm{~cm}$; Cook Medical).

A third ERCP was performed 2 days later because of recurrent respiratory distress. A $6-\mathrm{cm} \times 10-\mathrm{mm}$ WallFlex fully covered biliary stent (Boston Scientific) was placed in the common bile duct for drainage ( Fig.3). Following a period of improvement, on day 26 of the admission the patient was transferred to the intensive care unit where large amounts of bile were suctioned from the lungs. He died from respiratory failure within hours. 


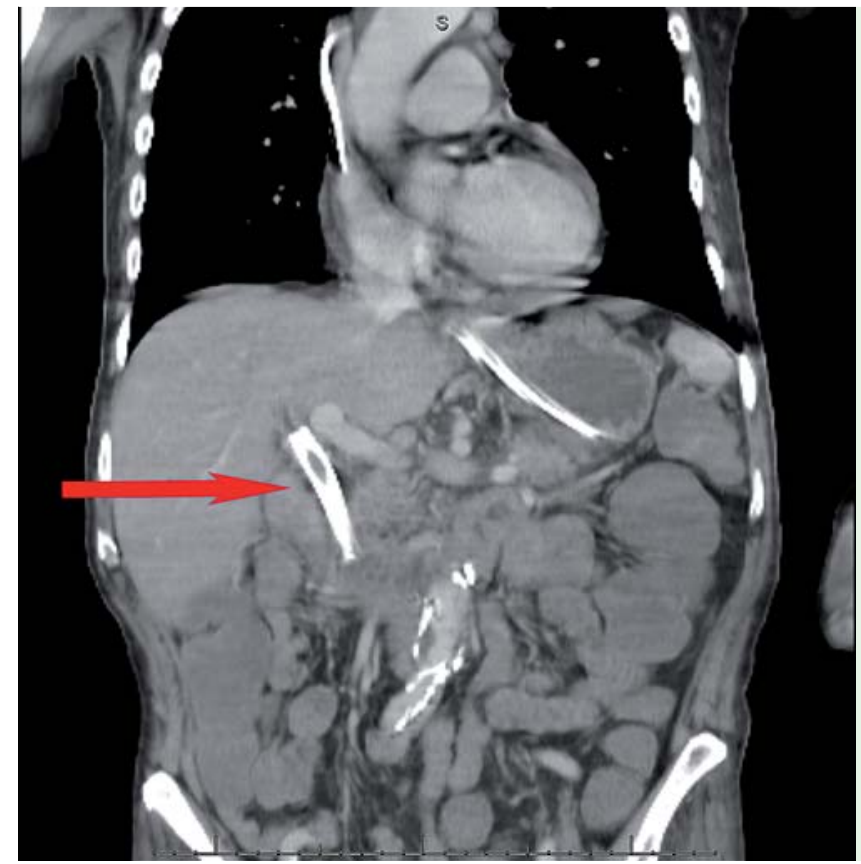

Fig. 3 Computed tomography (CT) scan following extraction of the old stent and placement of a fully covered biliary stent (arrow) showing the new stent correctly positioned within the common bile duct.

Diaphragmatic penetration by migrating biliary stents has never been reported. This case report clearly illustrates the need to remove a migrating stent, even after a prolonged asymptomatic period.

Endoscopy_UCTN_Code_CPL_1AK_2AD

Competing interests: None

\section{J. Antonsen ${ }^{1}$, L. Preisler ${ }^{2}$, U. Skram ${ }^{3}$, M. Klein ${ }^{1}$}

${ }^{1}$ Division of General Surgery, Copenhagen University Hospital, Herlev, Denmark ${ }^{2}$ Division of Hepato-Biliary Surgery, Copenhagen University Hospital, Rigshospitalet, Denmark

${ }^{3}$ Division of Intensive Care, Copenhagen University Hospital, Gentofte, Denmark

\section{Acknowledgments}

$\nabla$

The authors wish to thank Karen Bach of the Department of Radiology, Copenhagen University Hospital Gentofte for her contributions.

\section{References}

1 Johanson JF, Schmalz MJ, Geenen JE. Incidence and risk factors for biliary and pancreatic stent migration. Gastrointest Endosc 1992; 38: 341 - 346

2 Katsinelos P, Kountouras J, Paroutoglou G et al. Migration of plastic biliary stents and endoscopic retrieval: an experience of three referral centers. Surg Laparosc Endosc Percutan Tech 2009; 19: 217-221

3 Tarnasky PR, Cotton PB, Baillie J et al. Proximal migration of biliary stents: attempted endoscopic retrieval in forty-one patients. Gastrointest Endosc 1995; 42: 513-520

\section{Bibliography}

DoI http://dx.doi.org/

10.1055/s-0033-1344570

Endoscopy 2013; 45: E265-E266

(c) Georg Thieme Verlag KG

Stuttgart · New York

ISSN 0013-726X

\section{Corresponding author}

J. Antonsen, MD

Tagensvej 75, 3 tv

2200 København N

Denmark

Fax: +45-38684009

jacobantonsen@dadlnet.dk 